\title{
A STUDY ON THE EFFECT OF COMMUNICATION AND MONITORING TOOLS IN WEB-BASED TUTORING
}

\author{
F. Tajariol, ${ }^{*}$ J.-M. Adam, ${ }^{*}$ and M. Dubois**
}

\begin{abstract}
Among Web-based education activities, tutoring is considered to be very efficient. If many studies focus on learner's role, performance, andx satisfaction, many questions remain about the effect of the media communication on tutor-student interaction. We report on a study comparing tutor-students' interactions on a practical work session. Students and tutor are connected via audio-only or audiovideo links, with or without sharing visual information. Results show that tutors shift the contents of dialogue with students from procedural to contextual sentences, in order to the different media settings.
\end{abstract}

\section{Key Words}

Synchronous Web-based education, video-mediated communication, video-activity, video-presence

\section{Introduction}

Web-based technologies allow educational activities anywhere at anytime. If we know something more about student's activity, learning performance and satisfaction rating, many questions remain unanswered about the effect of communication and monitoring tools in the tutor-student-mediated interaction.

In this article, we present a study on tutor-learner dialogues in a practical work-learning scenario. In such a situation, tutor supervises students' activity by means of Web-based tools. Our aim is to understand how tutor adapt her assistance in a mediated interaction. We analyse the twofold role of the visual information: to show the presence of the other person and to share a working-visual environment. We first introduce the scientific context of our research. In the remainder of the article, we draw some features of visual information in video-mediated communication, with particular attention to the tutoring situation. We briefly show some inconsistencies of the video-mediated research methods. Next, we present our study concerning

* ARCADE Team, CLIPS-IMAG, Joseph Fourier University, Grenoble, France; e-mail: \{Federico.Tajariol, Jean-Michel. Adam\}@imag.fr

** Social Psychology Laboratory, Pierre Mendès-France University, Grenoble, France; e-mail: Michel.Dubois@upmf-grenoble.fr (paper no. 202-1336) the visual information in a synchronous practical session work. We conclude with a discussion about the role of visual information and we try to define some recommendations for Web-based education systems.

\subsection{A Web-Based Education Environment: Formid}

The growth in Web-based learning is a sign of the need to make education more flexible at the time and place, according to the students' needs. To answer to these needs, our team has been designing a Web-based education project called Formid [1]. The project is oriented to support practical works in a Web-based environment. In Formid project, tutor manages synchronous and asynchronous practical work sessions for 20 students. At the beginning of each session, tutor has to set on interactive pedagogical simulations by means of Java applet (e.g., simulation of a computer processing unit of an electrical field). At this stage, tutor prepares some exercises students are asked to solve during the practical work session. When the practical work session starts, tutor assists learner's activity by means of monitoring and communication Web-based tools. By monitoring tools we mean tools allow to provide tutor a visual information on learner's activity and allow her supervise working session. By communication tools we mean audio and video links allow tutor and student to share a social presence space. Up to now, the quality of video-mediated communication is forced by limits of Web network bandwidth. Previous researches in video-mediated literature show that, in a trade-off perspective, a high-quality audio link is more important than a sufficient video-mediated link [2]. In the Formid project, one of the most important issue is to analyse the effect of the communication and monitoring tools, so that to understand how tutor and student ground each other's knowledge and to establish an efficient interaction. This will have practical implications for the design of functions in the Web-based environment.

\subsection{What Do We Mean with Tutor's Activity?}

In Web-based education, tutor's activities are highly different: relational, institutional, organizational, pedagogical, 
etc. In this article we focus on tutor's cognitive activity: we analyse language tutor uses to assist learners and to explain concepts to them. Among the teaching activities, one-toone tutoring demands more participation from the teacher. On the other side, students are asked to be more active in their learning activity than in standard class activities [3].

The tutor's cognitive activity is twofold. On one side, tutor owns a technical background of scientific domains to give adequate instructions to students. On the other side, tutor owns a pedagogical experience and she knows how and when to explain concepts to students without disturbing their rhythm of learning.

The tutoring activity is highly collaborative. In fact, because tutor's aim is to improve students' knowledge, and is for this reason that tutor does not only instruct students giving them the solution to their exercises. Tutor monitors the student's comprehension so as to help them by explaining concepts and procedures. In this type of collaborative activity, communication is necessary, but is not enough: the essential process is common grounding $[4,5]$, that means using language to understand each other. Most researches focus on face-to-face tutor-student interaction [6], the use of language is to understand student's lack [7], and to explain learner concepts and procedures $[6,8]$. Results indicate that in a such face-to-face situation, tutor use visual and pragmatic cues to decide to help students without disturbing them during their work. In a Web-based-mediated interaction, tools do not support the cognitive richness of visual and pragmatic cues yet.

\subsection{Video-Mediated Communication as a Tool to Assist Learners}

In computer-mediated communication research, many studies focus on the effect of technology tools on communication structure. The researches concerning one-to-one mediated communication suggest that audio-video channel improves the quality of the communication in comparing to audio-only channel [8]. The function of the video-channel in communication processes is double [9]. Firstly, videochannel would build a feeling of presence of the partner, showing the speaker's gaze, facial expression, gesture and posture $[2,9,10]$, all cues to be used to monitor levels of comprehension [11]. Many experiments show that the first type of information, called video-presence [9], does not improve performances in a procedural task [13, 14], but it could be an important aid in cooperative problem solving $[10,15]$ and to lower the cognitive overload to manage the interaction [10,11]. Secondly, video-channel would build a shared visual space in the users' activity, showing objects and space in which each user works [10]. This type of visual cue, called video-activity [10], would be an essential aid to the coordination and communication processes between people working in a technology-mediated context $[10,12]$. Video-activity information makes easier grounding between partners [13], because it allows people sharing information about a topic, as they all know that the other one knows. Different communication media constraint different cognitive loads, so the cost of the grounding is different in order to the technique available with a specific medium [5]. In a visual shared space in mediated environments, people are able to perform their activity better [13]. Most researches analyse the effect of the communications media on the structure of the mediated interaction.

The length of dialogues, the number and frequency of turns and other pragmatic features are investigated to infer how communication technologies can support interaction $[9,11]$. The results show some inconsistencies due to the difference in the research methods. Sometimes the experimental conditions are not the same in all the studies, with difference in the quality of the communication tools (e.g., audio full- or half-duplex, different size of video, different frame rate). Moreover, the tasks used in the researches are highly different in their structural features; and, for instance, there is also little consistency in how dialogues are coded and analysed and about the interpretation of the results. Sometimes the number of interruptions is an indicator of ease of use of the VMC systems [14], sometimes as a proof of the lack of interaction [2]. This inconsistencies do not provide signs for the design of video systems. If most researches focus on the task performance, user satisfaction and communication process analysis, some researches concern the content of interaction in relation to the communication tool used $[10,15,16]$.

\section{The Research Questions of This Study}

In the video-mediated communication research, the general framework is based on comparing different communication media. In Web-based learning research, the most part of literature concerns learning performances [17], learner's satisfaction [18] or the usability and the effectiveness of the system [19]. Other researches focus on the tutor's structure of knowledge and on the remote assistance strategies delivered to a learner in a procedural task [20].

Our research questions in this article concern the effect of communication and monitoring tools on the structure and the content of the interaction, and we analyse how the tutor uses these tools to understand and to help learners.

\section{Method}

We report on this study that sets up a Web-based practical work session and focus on how tutor and students ground their utterances during tutoring dialogues.

\subsection{Hypothesis}

We present here the following hypotheses.

H1. About the effect of communication media on the structure of the interaction, according to the videomediated communication literature [2], we predict that audio-video turns, the length of dialogues and the number of words raise in audio-only and audio and video-presence conditions, in which tutor cannot observe student's activity. In these situations, the interaction would 
be more difficult for both participants and the common ground needs more verbal production.

H2. Concerning the content of the dialogue, previous researches $[10,20]$ show both the subjects adjust content in order to the availability of visual cues. We anticipate that in video-activity conditions tutor and students are likely to talk about the procedures rather than about the learner's context in audio and video-activity and in audio and video-presence, and video-activity conditions.

\subsection{Experimental Design and Conditions}

As mediated communication research shows, the experimental design is very expensive in terms of subjects and variables. For these reasons, in our design each tutor performs the tutoring task four times, one for each different condition, and each time she helps two new students. To guard against order effects, we randomly assigned tutors to each of the four conditions. We controlled tutors pedagogical experience, so that we split the tutors into two groups: long experience versus short experience. The students are all novice skilled in html programming (pre-tested) and they are randomly assigned to different conditions. Our experimental design consists of four conditions (Fig. 1):

Condition 1: Audio-only. The communication between the tutor and the students is conveyed verbally.

Condition 2: Audio+video-presence. The tutor and the students can see each other's face and upper torso by means of a second monitor, and they can communicate by means of the audio channel.

Condition 3: Audio+video-activity. The tutor can only see the students' computer screens, by means of $\mathrm{VNC}^{\mathrm{TM}}$, a tool of the type What-I-See-Is-What-You-See. They can communicate verbally by means of the audio channel.

Condition 4: Audio+video-presence+video-activity. The tutor observes students' computer screens and watches both student's face and upper torso on the personal monitor. Students can also see tutor's face and upper torso. They communicate each other by means of the audio channel.

\subsection{Subjects}

We recruited eight tutors, split in four women and four men, with good skills in html programming (M.Sc. and Ph.D. in computer science). All tutors own an expertise in teaching computer science subjects (almost one year). They received $45 €$ for all 4 -hour sessions. We also recruited 64 undergraduate students in psychology, split in 54 women and 10 men, all of them unskilled in html programming. Students received a credit for psychology course.

\subsection{Apparatus and Tasks}

In order to reduce the effects that might be attributed to technical limitations of bandwidth, we used an analogue audio-video link with broadcast quality for video and audio signals. Each room is equipped by an audio-only connection (a microphone and two sound speakers), which allows students and tutor to communicate verbally each other. The system allows tutor-one student dialogue at time, so the other student do not listen their dialogue. A video direct-link, composed by a digital video camera and a personal monitor, allows students and tutor to see each other's head and upper torso. Thus, the communication between tutor and learner is such a dyad. In all the rooms, the personal monitor is placed under the video camera, on the right of the computer screen. Each room is also equipped by a personal computer linked to Web network. On the tutor's workstation, a monitoring tool called $\mathrm{VNC}^{\mathrm{TM}}$ software, enables the tutor observing students' activity. The software is set on the observing-mode only: this means that no direct manipulation on learner' personal computer is possible. A commercial chat tool, $\mathrm{ICQ}^{\mathrm{TM}}$, allow tutor to receive help requests by students. On all computers,

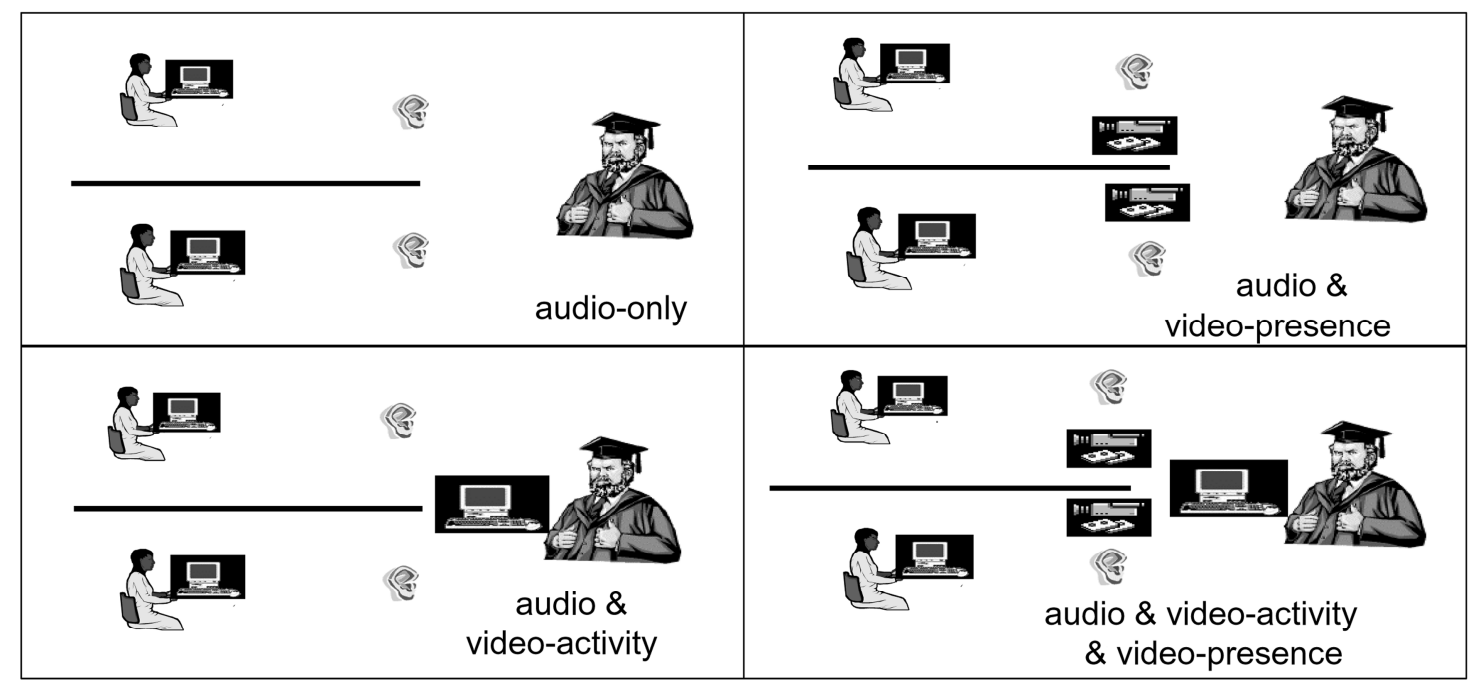

Figure 1. The four experimental conditions. 
an easy-to-use html editor (EditPlus) is available to write html codes and an Internet browser to visualize pages. Two folders contain exercises students have to solve in the practical session. At the beginning of the experimental session, students receive a four-page paper introduction to html tags. This document explains definitions of tags and shows some examples of the syntax, that is, for editing and hypertext linking.

\subsection{Experimental Task}

The students' aim of the practical session is to design an easy Web page. Students are briefed on the aim of the experimentation and they know their performances are not marked. Tutor is asked to monitor and to give assistance in the practical work session. Each student can ask tutor's help by writing in a chat box using ICQ. Tutor is forced to answer student by means of the audio-video link. No frames and instructions are given to tutors regarding how to manage session and about style of interaction towards students.

\subsection{Procedure}

Each experimental session $(n=32)$ lasts $1 \mathrm{~h}$. During the first phase $(15 \mathrm{~min})$, the researchers introduce the tutor to the two students and explain the aims of the experimentation. Then, tutor and each student are placed in separate rooms and are instructed on how to use the main functions of the apparatus. They fill-in a consent form and a pre-test questionnaire to test their knowledge of html programming. After that, the experimentation begins. Students start reading the four-page introduction to html and begin exercises. They can call tutor by means of the chat box. Tutor can supervise their activity and makes the decision to help them at will, on tutor's own initiative or because students have been asking for aid. At the end of $35 \mathrm{~min}$, the experimental session is over. The tutor and the students are asked to complete a questionnaire concerning the tools of communication, the awareness of the other person, and other items about their feelings on the experimentation. Students take a post-experimentation questionnaire to test their html programming improvement.

\subsection{Measures}

We videotaped tutor-students' interaction. All sessions were transcribed verbatim for a post-experimental coding. We performed a quantitative analysis, counting different pragmatic features. In this article we report number of words, of turns, and the length of dialogues for each condition. We also conducted a qualitative analysis on verbatim transcriptions and videotaped actions, by means of a grid inspired on specific literature [21]. In our coding scheme, each utterance was classified as a question or an answer in one of the following categories:

- Contextual information, that is any utterance tutor and students produce about the student's activity stage (e.g., the interface state, the html document state).

- Procedural information, any information students need to perform the html task (e.g., syntax rules and html tags, software functions).

We also recorded learner's activity on the personal computer by means of a special software (Snag-It $\left.{ }^{\mathrm{TM}}\right)$. In this article we only report on the first level of qualitative coding. Two independent coders classified each utterance ( $\mathrm{K}$ de Cohen $=0.85$ ). We collected measures of task performance, concerning the number of correct tags students inserted in their Web page and their answers to the post-experimentation test. We also collected answers to a post-task questionnaire, about students-tutors' feelings of this experience. We do not analyse these data in this article.

\section{Results}

The experimental design is a complete factorial in which we compare communication tools (audio-only versus audio-video) and monitoring tools (with versus without). We conducted a between-subject analysis of variance (ANOVA) across the four conditions audio versus audio and video-activity versus audio and video-presence versus audio and video-activity and video-presence. We present the results according to our hypotheses.

\subsection{The Effects of the Tutoring Tools on the Structure of the Interaction}

We found no significant differences on the measures concerning the number of words, the length of the dialogues and the number of audio-video turns. The number of the audio-video turns was higher in the audio and videoactivity condition than the audio-only condition, but it did not differ from one another (Table 1 ).

\subsection{The Effects of Tutoring Tools on the Content of Tutor-Student Dialogues}

We coded questions tutor (students) asked students (tutor) and answers that students (tutor) gave tutor (students). About tutor, as shown in Fig. 2, the tutoring tools have a statistically significant simple effect across conditions on the number of questions tutor asks students $[F(3,28)=3.686 ; p<0.03]$. Post hoc test indicated that audio and audio and video-presence conditions contain more questions about context than both audio and video-activity and audio and video-activity, and video-presence conditions.

About students' language, in both audio and video-activity and audio and video-activity, and videopresence conditions $(M=17.66$ and 19.8), students produce less answers than audio and audio+videopresence conditions $(M=37.33$ and 34$)$. The difference 
Table 1

Effects of Different Media Conditions on the Quantitative Data ( $M=$ Mean; SD = Standard Deviation)

\begin{tabular}{|l|l|l|l|l|l|}
\hline & \multicolumn{1}{|c|}{ Audio } & $\begin{array}{c}\text { Audio and } \\
\text { Video-Presence }\end{array}$ & $\begin{array}{c}\text { Audio and } \\
\text { Video-Activity }\end{array}$ & $\begin{array}{c}\text { Audio and Video- } \\
\text { Presence, and } \\
\text { Video-Activity }\end{array}$ & $\begin{array}{c}\text { Snedecor's } F \text { and } \\
p \text { Values }\end{array}$ \\
\hline Number of words & $\begin{array}{c}M=1,490.375 \\
\mathrm{SD}=1,201.5\end{array}$ & $\begin{array}{c}M=1,981.75 \\
\mathrm{SD}=1,330.175\end{array}$ & $\begin{array}{c}M=1,869.375 \\
\mathrm{SD}=1,027.86\end{array}$ & $\begin{array}{c}M=1,423.75 \\
\mathrm{SD}=670.1\end{array}$ & $F(3,28)=0.515 ;$ n.s. \\
\hline $\begin{array}{l}\text { Length of dialogue } \\
\text { (seconds) }\end{array}$ & $\begin{array}{l}M=595.7 \\
\mathrm{SD}=682.875\end{array}$ & $\begin{array}{l}M=775.875 \\
\mathrm{SD}=558.25\end{array}$ & $\begin{array}{c}M=860.125 \\
\mathrm{SD}=629.75\end{array}$ & $\begin{array}{c}M=642.625 \\
\mathrm{SD}=402.43\end{array}$ & $F(3,28)=0.353 ;$ n.s. \\
\hline $\begin{array}{l}\text { Number of audio-video } \\
\text { turns }\end{array}$ & $\begin{array}{l}M=4.375 \\
\mathrm{SD}=1.768\end{array}$ & $\begin{array}{l}M=5.5 \\
\mathrm{SD}=2.138\end{array}$ & $\begin{array}{l}M=7.125 \\
\mathrm{SD}=4.05\end{array}$ & $\begin{array}{c}M=6.375 \\
\mathrm{SD}=3.335\end{array}$ & $F(3,28)=1.271 ;$ n.s. \\
\hline
\end{tabular}

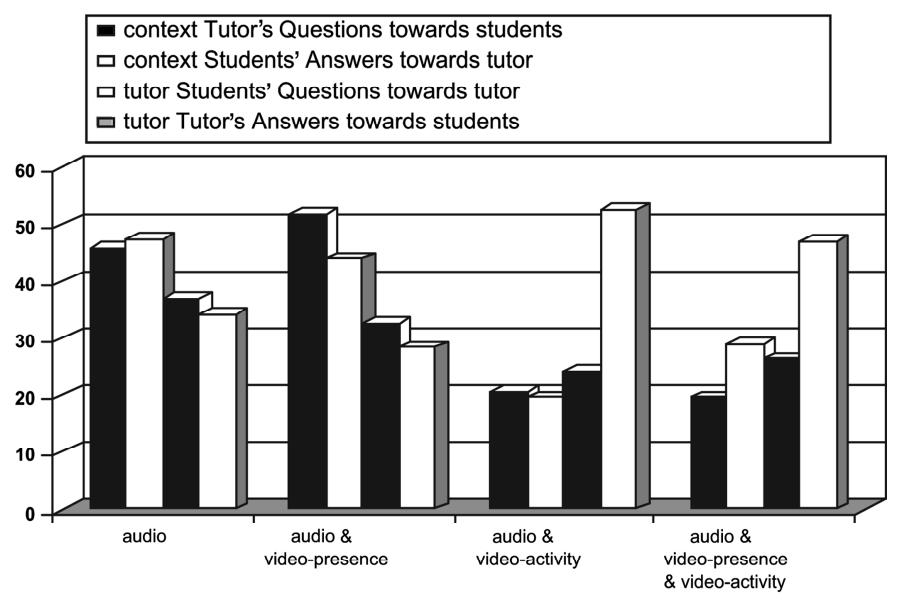

Figure 2. Effects of different media conditions on the categories of dialogue.

is significant $[F(3,28)=3.686 ; p<0.03]$. Thus, in the audio and video-presence condition tutors produce more questions and explanations on students' learning context than in the audio and video-activity condition $[t(10)=7.857 ; \quad p<0.04 ; \quad M=41.8$ versus 10.33$]$. With regard to the procedural category, we found no significant differences across different conditions.

\section{Discussion}

The aim of this research was to analyse the effect of communication channels on the tutor-students dialogues, and to analyse how tutor can adapt his/her assistance in order to different media of communication. We discuss the results to our two hypotheses in the following. The results concerning the structure of the mediated communication do not support our hypothesis. In the audio-only experimental condition, tutor can only use language to understand the learner's context activity and at the same time she has to explain rules and procedures about. As we explained in the tutoring task section, tutoring is a very demanding activity for both students and tutor. How could we explain this result? A possible explanation is due to the type of the task demanded to subjects. For learners: they are not asked to be passive, waiting for tutor's help to solve their exercises. In fact, they appeal to tutor over html tags and they focus on tutor's explanations. About tutor: she uses language to give friendly and human support, to encourage them during the session and to assist them by technical explanations. So, the participants do not change the quantitative production of language. The results about effect of tools on the content of tutor-student's interaction would support our hypothesis. On the other side, the different levels of media integration (video/data-presence and audio) provokes an effect only on the quality of dialogue. In fact, in the experimental conditions without video-activity information, tutor is forced to build a mental representation of the learner's context by asking students. So, tutor has to use language to ask learner's context, but she does not reduce the quantity of turns intended to explain the html rules and procedures. Secondly, we could argue that tutors and students adjust their dialogues in different manners (Table 1). They use language in different communication settings. In the conditions without video-activity tutors need especially contextual information, to understand how and when to help students. We also note that there is no statistically significant difference between the audio-only and the audio and video-presence conditions. It seems that the other's face in a tutoring task does not allow the tutor to be more proactive towards the student's needs [10].

\section{Conclusion}

The results we present in this article show that communication and monitoring tools can impact how tutor and students ground their mutual understanding in a practical work Web-based session. These findings, linked to other experiments we have been performing in our laboratory suggest some recommendations for the design of Web-based education systems.

Video-activity features would seem the most important information for tutor in such a situation. In fact, When video-activity is not available to tutor, she needs to take time to ask students. Anyway, in a virtual 20-students large-size classroom, the video-activity information becomes a risk for cognitive overload for tutor. So that, a Web-based education system must support ergonomic techniques for visualizing student's activities.

Qualitative analysis shows video-presence information does not enable tutor and students to ground as much 
as video-activity. This is a good answer to the trade-off of the limits of bandwidth network, even if recently some Web-based education environment enables video-presence information.

\section{Acknowledgements}

We gratefully acknowledge for their support Brigitte Meillon and Martine Harsch (Multicom Team-CLIPS Lab).

\section{References}

[1] http://www-clips.imag.fr/arcade/projets/FORMID/ FORMID.html.

[2] S. Whittaker \& B. O'Connaill, The role of vision in face-toface and mediated communication, in K.E. Finn, A.J. Sellen, \& S.B. Wilbur (Eds.), Video-mediated communication (New Jersey: Lawrence Erlbaum Associates, 1997), 23-49.

[3] P.A. Cohen, J.A. Kulik, \& C.C. Kulik, Educational outcomes of tutoring: A meta-analysis of findings, American Educational Research Journal, 19, 1982, 237-248.

[4] H.H. Clark, Using language (Cambridge: Cambridge University Press, 1996).

[5] H.H. Clark \& S.E. Brennan, Grounding in communication, in J. Levine, L.B. Resnick, \& S.D. Behrend (Eds.), Shared cognition: Thinking as social practice (Washington, DC: APA Books, 1991).

[6] A.C. Graesser, K.P. Natalie, \& P.M. Joseph, Collaborative dialogue patterns in naturalistic one-to-one tutoring, Applied Cognitive Psychology, 9, 1995, 495-522.

[7] M.T.H. Chi, N. De Leeuw, M.H. Chiu, \& C. Lavancher, Eliciting self-explanations improves understanding, Cognitive Science, 18(3), 1994, 439-477.

[8] M.T.H. Chi, M. Bassok, M.W. Lewis, P. Reimann, \& R. Glaser, Self-explanations: How students study and use exemples in learning to solve problems, Cognitive Science, 13(7), 1989, 145-182.

[9] W.A.S. Buxton, A.J. Sellen, \& M.C. Sheasby, Interfaces for multiparty videoconferences, in K.E. Finn, A.J. Sellen, \& S.B. Wilbur (Eds.), Video-mediated communication (New Jersey: Lawrence Erlbaum Associates, 1997), 385-400.

[10] R.M. Kraut, M.D. Miller, \& J. Siegel, Collaboration in performance of physical tasks: Effects on outcome and communication, Proc. of the CSCW' 96 Conf. on Computer Supported Cooperative Work, New York, ACM, 1996, 57-66.

[11] A.J. Sellen, Remote conversations: The effects of mediating talk with technology, Human-Computer Interaction, 10, 1995, 401-444.

[12] B. Nardi, A. Kuchinsky, S. Whittaker, R. Leichner, \& H. Schwarz, Video-as-data: Technical and social aspects of a collaborative multimedia application, in K.E. Finn, A.J. Sellen, \& S.B. Wilbur (Eds.), Video-mediated communication (New Jersey: Lawrence Erlbaum Associates, 1997), 487-517.

[13] S. Whittaker, E. Geelhoed, \& E. Robinson, Shared workspaces: How do they work and when are they useful?, International Journal of Man-Machine Studies, 39, 1993, 813-842.

[14] B. O'Connaill, S. Whittaker, \& S. Wilbur, Conversations over videoconferences: An evaluation of video-mediated interaction, Human-Computer Interaction, 8, 1993, 382-428.

[15] E. Boyle, A. Anderson, \& A. Newlands, The effects of eye contact on dialogue and performance in a co-operative problem solving task, Language and Speech, 37(1), 1994, 1-20.

[16] H. Ishii \& M. Kobayashi, ClearBoard: A seamless media for shared drawing and conversation with eye-contact, Proc. of the Conf. on Human Factors in Computing Systems CHI '92, ACM, 1992, 225-232.

[17] S.R. Hiltz, Correlates of learning in the virtual classroom, International Journal of Man-Machine Studies, 39, 1993, $71-98$.

[18] P. McAndrew, S.P. Foubister, \& T. Mayes, Videoconferencing in a language learning application, Interacting with Computers, 8(2), 1996, 207-217.

[19] A. Gnisci, F. Papa, \& S. Spedaletti, Usability aspects, socio-relational context and learning performance in the virtual classroom: A laboratory experiment, Behaviour and Information Technology, 18(6), 1999, 431-443.

[20] L. Karsenty, Cooperative work and shared visual context: An empirical study of comprehension problems in side-by-side and remote help dialogues, Human-Computer Interaction, 14, 1999, 283-315.

[21] R.M. Pilkington, Intelligent help facilities: Communicating with knowledge based systems (London: Paul Chapman Publishing Ltd., 1992).

\section{Biographies}

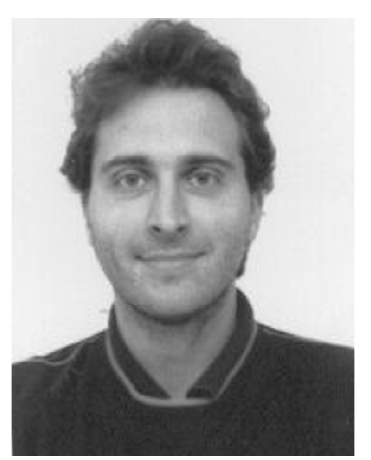

Federico Tajariol is a Ph.D. candidate in cognitive science at the Joseph Fourier University, Grenoble, France. He is a researcher of Arcade team in the Clips-Imag Laboratory. His research interests are focused on cognitive ergonomics issues in the Web-based education systems.

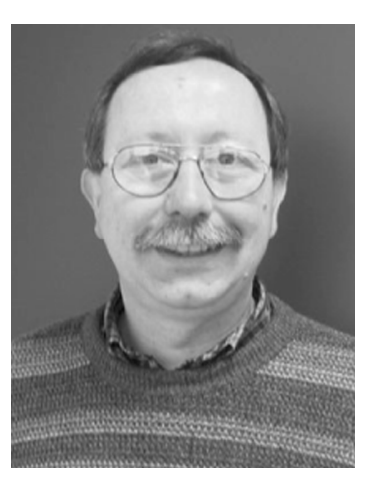

Jean-Michel Adam is a Lecturer in Computer Science at the Pierre Mendès-France University, Grenoble, France. He is a researcher of Arcade team in the Clips-Imag Laboratory. His research concerns software for Web-based interactive learning systems and the facial interaction in the video-mediated education systems.

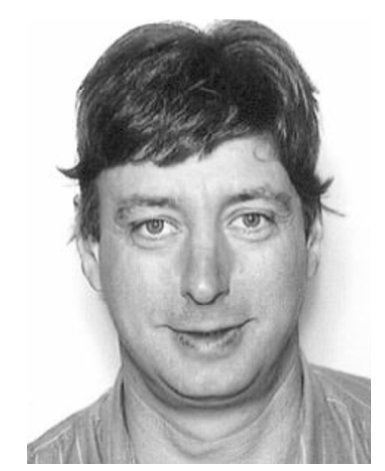

Michel Dubois is a Lecturer in Social and Work Psychology at the Pierre Mendès-France University, Grenoble, France. He is a researcher of the Social Psychology Laboratory. His research concerns socio-cognitive issues in educational multimedia and the relationships between emotions and cognition in video-mediated communication systems. 